\title{
Cuentos y Leyendas
}

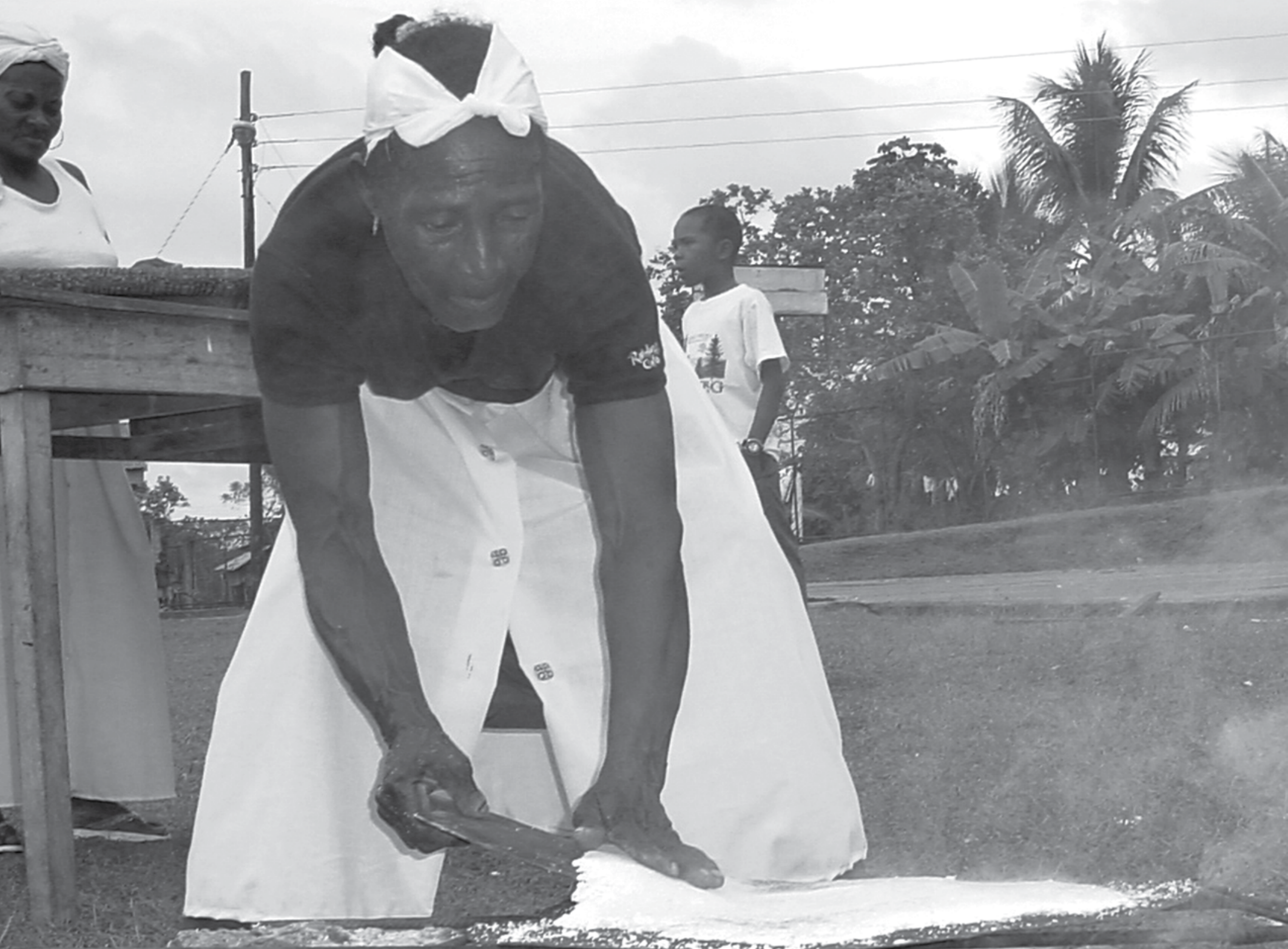

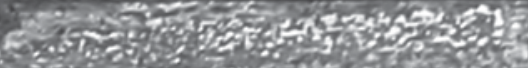

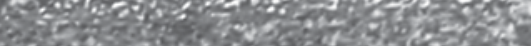

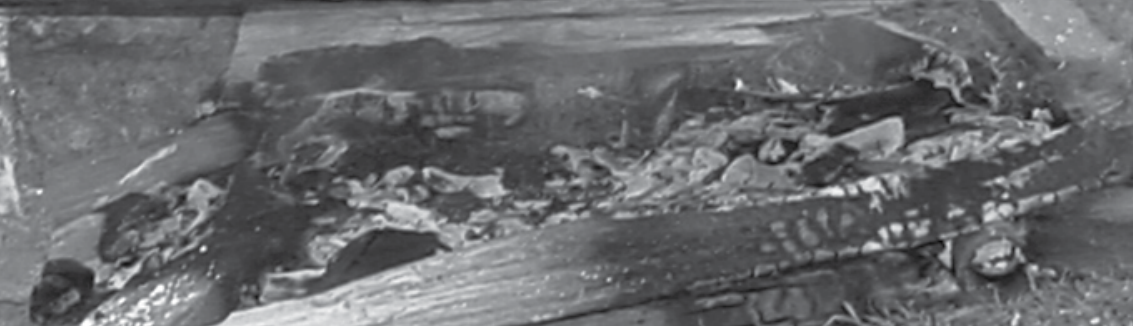




\section{Letras prohibidas}

\section{Daniel García Jiménez}

¡Todos de pie! Exclamó furibundo el padre Hilario. A continuación se escuchaba el coro atronador:

_. Arrepentíos pecadores!

Los fieles se hincaban una y otra vez repitiendo sin cesar la letanía.

¡Dios mío perdona nuestros pecados! ¡Arrepentíos pecadores! Gritaba con insistencia el sacerdote.

Un día antes, en la esquina opuesta de la iglesia, habían encontrado 400 ejemplares del Kama sutra con el título: "100 excitantes posturas", mientras en la casa parroquial aun no se vendían los mil ejemplares de la novena a la virgen, razón por la cual, los monaguillos y el sacristán de la iglesia habían sido puestos en penitencia, caminando descalzos sobre piedras de hormigón en la plaza pública, como una forma de mortificar las pasiones y apagar los apetitos de la carne.

Los caballeros del Santísimo y la Congregación Mariana, dirigidas por el juez de mesta del pequeño poblado, señalaban a Herculino de la Torre, salvadoreño, nacionalizado nicaragüense, masón y dueño de la única librería, de ser el autor de la conspiración. Era muy conocida su posición anti católica al exaltar la capacidad de la mente y la lógica; sin tomar en cuenta la necesidad de la gracia y la misericordia divina en nuestra realización y salvación, ignorando la realidad del pecado.

Todos los dedos acusadores señalaban a de la Torre de ser el dueño de la literatura pecaminosa que había generado un ambiente de lascivia en el pueblo que se había caracterizado por su devoción religiosa, conservando sus costumbres desde tiempo de la Colonia. ¡Hay que llevar a la hoguera a ese hijueputa de Herculino!, decía el juez de mesta.

Era 1940, las encíclicas del Papa Eugenio Pacelli (Pío XII) sobre la moral recorrían el mundo. En esos días, las calles polvorientas del pueblecito se alborotaban por las tardes cuando en procesión salían todas las beatas de la ciudad, rezando el santo rosario para sacarles el demonio a todos los parroquianos que se habían desenfrenado con aquel manual que incitaba al pecado. A pesar de las insistentes procesiones, vigilias, ayunos, penitencias y flagelos que reventaban las espaldas de los parroquianos sospechosos de los desvaríos, en el río no dejaban de aparecer a lo largo de los cercos de alambres de púas; brasieres de variados colores, corpiños, fustanes, calzones, y ejemplares del kamasutra con páginas arrancadas.Una que otra chinela flotaba en el río de vez en cuando, las que eran recogidas con sumo interés por el sargento Beteta para hacer las correspondientes investigaciones de aquellos actos bochornosos, que atentaban contra la moral y las buenas costumbres. Más de una vez se le vio por el caserío haciendo las correspondientes averiguaciones, aunque no encontrara a ninguna de las dueñas.

De repente el pueblo amaneció más perturbado, sólo mujeres había en las calles, lucían angustiadas porque los hombres habían huido. Mientras la librería ardía en llamas, se escuchaban disparos, ladridos de perros, trotar de caballos, la gente comentaba que en el río habían aparecido las sandalias de la esposa del comandante de la guardia y el calzón de la mujer del alcalde.

Masaya, Diciembre del 2013. 


\title{
El árbol de monedas
}

Heber Masís Obregón

\begin{abstract}
llá por el año de 1944 era un niño que tenía 6 años, estaba en preescolar en la escuela del "barrio Loco" Adonde la Sofillita Flores. Niño de buenos modales educado familiarmente, respetuoso de los mayores, saludaba a todos los zapateros que habían en mi casa "Fábrica de Calzado VALSIS" y mi tío José de Jesús Masís López me hacía que le diera el saludo como a mi papá con las manos puestas, buenos días, entre los zapateros había uno que me era muy simpático se llamaba Miguel, tenía una sonrisa y risa de payaso, una boca grande, todo el tiempo estaba sonriendo o cantando, molestaba a uno que le decían "el loco" cantando: dicen que estamos locos, locos, relocos y repetía la canción hasta hacer explotar al otro en ira, una vez intervino mi papá Francisco Masís para que no hubiera una tragedia, pués David a quién le decían "Loco" agarró un garrote para pegarle a Miguel, y dejó de cantar, este me llevaba jocotes, me daba mamones y me pedía pan, azúcar o cualquier cosa.
\end{abstract}

Una vez me confió un secreto para que yo pudiera tener muchos reales (monedas); pero, que no se lo contara a nadie porque si lo contaba no se realizaría el milagro y consistía en que yo metiera la mano en el escritorio de mi papá y agarrara un puñado de monedas y las sembrará en el tronco del árbol de naranja que había en el patio de la casa, que lo hiciera cuando nadie me viera porque si me veían no nacía el árbol de reales (monedas), y así lo hice en un descuido agarre un puñado de monedas y me las eché a la bolsa, las envolví en un papel y durante la noche las sembré a orillas del tronco del árbol de naranja, todos los días me asomaba si había nacido el árbol de reales y le preguntaba a Miguel por que no había nacido y me contestó que a la primera no siempre nacían, que volviera a sembrar otra puñada y lo hice una, dos, tres veces a la cuarta vez mi primo Manuel Rodríguez Campos me preguntó que estaba haciendo y le conté, este era mayor que yo tenía como 11 años y me dijo que las monedas no son semillas por eso no nacían y que Miguel era un mentiroso que él cuando vos vas al colegio las desentierra, te engañó.

"No Creas todo lo que digan menos secretos.

Las Mentiras tarde o temprano se descubren." 


\section{Zapatitos de un niño}

kevin Ramírez ${ }^{1}$

-Anda, trae a tu papá, se escuchó desde la cocina la voz de su mamá. Sin perder tiempo se puso una camiseta sucia y salió como era de costumbre todos los sábados y domingos a buscar a su papá; un trabajador de la mina "El Becerro", seguramente se encontraba en el bar de la Paula, gastando el poco dinero que había ganado en la semana, en la mesa quedaba una tarea de matemáticas a medio terminar, un lápiz de grafito y un borrador. Hoy no salió renegando como otras veces lo hacía, hoy estaba contento porque era su cumpleaños y su papá le había prometido comprarle un par de zapatos para ir a la escuela, porque los que tenía a fuerza de uso estaban despegados y gastados y en clase sus compañeros se burlaban de él, y en más de una ocasión la profesora le llamó la atención por no llevar el uniforme y por llegar de chinelas a clases, sin comprender que sus ganas de estudiar eran mucho mayores que la mala vida que le diera su infeliz padre, un borracho empedernido que le decía que la escuela era una pérdida de tiempo y que no pensaba gastar un peso en "esa tontería". A pesar de todo, su mamá lo apoyaba y en medio de cientos de privaciones y sabiendo que su esposo faltaría como siempre a su promesa, le había comprado un par de zapatitos, no eran lujosos ni caros, pero bien sabía la cara de alegría que su hijo pondría al verlos, esa sonrisa que para ella era todo y le permitía sobrellevar la vida que tenía. Al llegar al bar de la Paula, el niño encontró como siempre a su padre, caído en el suelo, sucio, hediondo y borracho, con más cariño que de costumbre levantó a su papá y lo llevó tambaleante por el camino a su casa.

-Papá, ¿Sabes qué día es hoy?

¡¡ Es domingo!

-Sí, pero ¿Qué fecha?

¡¡Yo qué voy a saber! Dejá de molestar.

-Pá, hoy es mi cumpleaños.

$-i Y ?$

-Usted me prometió ir a Somotillo a comprarme zapatos.

-¡Vos estás loco! ¿Me ves la cara de banco, o qué? Además, ¿para qué quieres zapatos? Para seguir perdiendo tiempo en esa escuela. El niño triste y molesto, empezó a caminar más rápido y no logró ver el furgón que venía por la carretera, el chofer, al ver de repente al niño lo quiso esquivar, pero fue inútil, no pudo evitar arrollar al niño para luego estrellarse en un árbol de tigüilote a la orilla del camino, el estruendo hizo salir a las personas de sus casas y al llegar al lugar del accidente se encontraron con la desgarradora escena, el padre medio borracho llorando sobre el cuerpo de su hijo y su madre inconsolable junto a ellos.

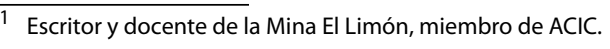

